\title{
Shifting Life Attitudes during the First Lockdown Due to COVID-19 Pandemics. A Naturalistic Comparative Study
}

\author{
Juan Valdés-Stauber1 ${ }^{*}$, Jakob Böttinger ${ }^{2}$, Sarah Kramer ${ }^{2}$ \\ ${ }^{1}$ Department of Psychiatry and Psychotherapy I, University of Ulm, Ulm, Germany \\ ${ }^{2}$ University of Ulm, Ulm, Germany \\ Email: ^juan.valdes-stauber@zfp-zentrum.de, jakob.boettinger@uni-ulm.de, sarah.kraemer@uni-ulm.de
}

How to cite this paper: Valdés-Stauber, J., Böttinger, J., \& Kramer, S. (2022). Shifting Life Attitudes during the First Lockdown Due to COVID-19 Pandemics. A Naturalistic Comparative Study. Psychology, 13, 233-253. https://doi.org/10.4236/psych.2022.132013

Received: December 9, 2021

Accepted: February 19, 2022

Published: February 22, 2022

Copyright (อ 2022 by author(s) and Scientific Research Publishing Inc. This work is licensed under the Creative Commons Attribution International License (CC BY 4.0).

http://creativecommons.org/licenses/by/4.0/ (c) (i) Open Access

\begin{abstract}
Background: The COVID-19 pandemic is one of the major tragedies for humanity since World War II because of its global threat both to global health and to the socio-economic basis of the entire world. There are investigations about protective and straining factors as well as about coping mechanisms, but little was investigated about changes in attitudes or value-based behaviour. Objective: The aim of this investigation was to assess the impact of lockdown expressing the new threat due to pandemics on life attitudes and on reflecting dimensions about the real finiteness of life. Method: This prospective, naturalistic, and comparative study began in November 2019 with the aim to examine the life attitudes and the pattern of confrontation with the death of young and middle-aged adults in the general population. At the time point of lockdown in Germany (March 23, 2020), participants were in addition assessed about the impact by pandemics on value-based responses. Participants $\left(N=302, n_{1}=116\right.$ before, $n_{2}=186$ during lockdown) were compared by means of Life Attitude Profile (LAP-R) and Anticipatory Farewell to Existence Questionnaire (AFEQT). Comparisons were computed by means of bivariate, multivariate and multinomial models. Results: Subsample during lockdown is older, besides no differences in socio-demographic, health and personality profiles. During lockdown, sample shows higher scores in LAP-R for the dimensions "death acceptance" and "goal-seeking"; in AFEQT for "metaphysical rise" and "altruistic preoccupation". The higher "death acceptance" "charity" "fulfilment of existence" and "self-efficacy", the less likely a person is to report that a pandemic influences her or his appraisal of value-based questions. Conclusions: These results indicate that lockdown conditions following the COVID pandemic have led to more intensive awareness about the mortal condition and the focus on relevant others. The question that arises is
\end{abstract}


whether pandemics could urge people to reappraise the existential purposes and priorities, and independently of personality traits.

\section{Keywords}

COVID-19 Pandemic, Lockdown, Life Attitudes, AFEQT, Death Acceptance, Self-Efficacy

\section{Introduction}

As of $1^{\text {st }}$ January 2022, according to the Dashboard of Johns Hopkins University, there have been almost 285 million COVID-19 cases reported worldwide and 5.44 million deaths (1.9\% of infected individuals). The COVID-19 pandemic is one of the major tragedies for humanity since World War II because of its global threat to mental and physical health, social stability and socio-economic conditions. Inequalities, national selfishness, destructive populism, and the radical uncertainty about the future of mankind arise. The COVID pandemic, as every pandemic since ancient times, affects both society and individuals, "the universe of certainty crumbles and the awareness of death deeply touches individuals. COVID-19 is a disease of remarkable symbolism, primarily loneliness, especially for dying isolated in intensive care units, and also painful finitude because of the "respiratory death marked by air hunger" (Breitbart, 2020). Cities, regions, and countries deploy measures that try to balance economy, financial support, medical resources, and restrict autonomy. Daily rituals and traditions that provide stability are broken. The anthropological-based need for creating new rituals is an ongoing endeavour within lockdown and confinement periods as well as within the so-called "new normal" characterized by face masks, social distancing, and permanent disinfection, "when these rituals go missing, there is something resourceful and insistent in the human spirit requiring us to create rituals anew" (Imber-Black, 2020). In a meta-analysis about 25 longitudinal studies involving 72,004 individuals, "the psychological impact of COVID-19 lockdowns is small in magnitude and highly heterogeneous, suggesting that lockdowns do not have uniformly detrimental effects on mental health and that most people are psychologically resilient to their effects" (Prati \& Mancini, 2021). In Germany, a cross-sectional survey was conducted during and after the lockdown $(\mathrm{N}=1538)$ using a questionnaire test battery including a novel measure of acute COVID-19 stress, meaningfulness and crisis of meaning (SoMe), self-control (SCS-KD), and a screening of general mental distress, measured by core symptoms of depression and anxiety (PHQ-4), concluding: "also in the present study among German-speaking participants, general mental distress was high. Scores were higher after than during the lockdown, indicating an ongoing destabilization for a significant part of the population. People who saw meaning in their lives and who were capable of self-control reported substantially less mental distress. Meaningfulness and self-control also served as buffers 
between COVID-19 stress and general mental distress, when COVID-19 stress was high, the presence of meaningfulness and self-control accounted for lower general mental distress. Moreover, people who suffered strongly from COVID-19 stress were more likely to develop a crisis of meaning which, in turn, was associated with higher general mental distress. This suggests that ongoing anxiety and depression might (also) be based on existential struggles" (Schnell \& Krampe, 2020). The internal locus of control seems to be protective whereas the external locus of control is associated with symptoms of depression and anxiety facing the COVID-19 threat (Krampe et al., 2021).

Every country in the world is now experiencing different epidemic waves, with each relevant variant bringing new challenges such as quite different contagiousness and pathogenicity patterns. Health systems are at times overwhelmed, professionals exhausted and, at least in Western societies, divided over the benefits of vaccionarion. Vaccination has proven to reduce severe morbidity and mortality, yet there are many anti-vaccinationists who question the scientific information, pursue conspiratorial ideas or follow an individualistic and solipsistic logic.

The COVID-19 pandemic has exposed the vulnerability of the human psyche and of social and economic structures, and alternately the capacity of humans for solidarity and unsolidarity. Apart from those who died from Corona, there are many losers from the pandemic, especially lonely elderly people, children and young people, and people who lost their jobs and suffer drastic financial losses.

The physical and psychological consequences of lockdown, quarantine, social isolation, social tension and long COVID are now well known. Besides social distancing, masks and vaccinations, we do not have prophylactic and pharmacological tools, although initial licences offer some hope. The future is uncertain at the individual, collective, national and global levels.

The order of the day is to persevere and to redefine interpersonal contacts at 1.5 metres distance. Beyond the psychological and physical threats as well as the moral imperatives to contain the epidemic spread in favour of the weaker, the question is what values provide the necessary support to persevere and to remain resilient; possible intuitive candidates are frugality, hope, helpfulness, solidarity, positive attitude to life and at the same time, preparedness to accept adversity, pragmatism, self-efficacy beliefs, optimism or meaningfulness.

This paper hypothesizes that value-based life attitudes are robust traits of the individuals, but that the COVID-19 pandemic poses a particular threat at the individual and collective level, which may lead to a change in the personal hierarchy of values or to a consolidation of beliefs. This paper reanalyzes data from an ongoing study on life attitudes towards death at different ages. Since the lockdown was unexpected, the naturalistic design was adapted to the new situation: Comparison regarding life attitudes between individuals interviewed before the lockdown and during the lockdown. As the individuals were different, the comparison was statistically controlled with personality and socio-demographic variables in multivariate models. The age groups are those that were already included in the original design. 


\section{Background}

The transmembrane spike glycoprotein (called "S protein") accounts for the crownlike appearance of coronaviruses. This heavily-glycosylated, cell-surface protein has two distinct functional domains, named S1 and S2, which are necessary for a coronavirus to enter a cell. S1 contains the receptor binding domain (RBD) and acts in the initial stages of fusion with human cells, whereas S2 is necessary for continuing infiltration. $S$ protein must be splitted by proteases, including transmembrane protease, serine 2 (TMPRSS2) and cathepsin, like for severe acute respiratory syndrome coronavirus 1 (SARS-CoV-1). Of note, the $\mathrm{S}$ protein of SARS-CoV2, the virus that causes COVID-19, contains a furin cleavage site (Coutard et al., 2020). Furin cleaves and preactivates the $S$ protein, especially in the respiratory system, and markedly enhances the ability of SARS-CoV-2 to bind to its cell surface receptor, namely angiotensin-converting enzyme 2 (ACE2). This affinity explains the increased expansion and pathogenicity of SARS-CoV-2. Furthermore, this virus threatens humanity due to a 12-nucleotide mutation (ccu cgg cgg gca) encoding four amino acids that enhance the ability of Furin to cleave and preactivate the S protein (Shang et al., 2020). These 12 biological letters have changed the world and the everyday self-evidence of communitarian human life.

The scope of the clinical expression of COVID-19 is primarily mediated by the distribution of ACE2 receptors in humans (Vetter et al., 2020). The immunological responses to SARS-CoV-2 are both the innate (mediated by macrophages, $\mathrm{CD}^{+} \mathrm{T}$ cells, interleukins, and cytokines) and adaptive (specific antibodies) immune systems. Different hypotheses stress the role of hyperinflammation, cytokine storm, and overshooting or dysfunctional antibody reaction as possible pathogenic pathways (Vardhana \& Wolchok, 2020). That is the reason why corticosteroids may ameliorate some dramatic courses of the illness. Today, biological research assumes that dramatic courses of illness could be rather explained from a systemic point of view: an immunological response is trapped in a continuous loop between overactivation and inhibition (Schulte-Schrepping et al., 2020). Just overshooting an immunological reaction could trigger endothelial lesions and cause microembolism as well as disseminated intravascular coagulation and, therefore, multiorgan failure (Helms et al., 2020; Klok et al., 2020; Tang et al., 2020; Tay et al., 2020). Epidemiologists try to mathematically model this medical, individual, and social tragedy towards defining risks, to assess testing strategy and the effectiveness of measures, and to explore at different levels the progression of a pandemic. The most relevant indicators are the infection fatality rate (IFR, with regard to positive testing), case fatality rate (CFR, with regard to COVID-19 patients), basic reproduction number $\left(\mathrm{R}_{0}\right)$, effective reproductive number $\left(\mathrm{R}_{\mathrm{eff}}\right)$, herd immunity, and epidemic growth curves, but also test parameters like sensitivity, specificity, and-especially important to assess cluster risks-the positive and negative predictive values. Important research deals with the extent of the immune response, disease severity, and mortality (Gudbjartsson et al., 2020; Hauser et al., 2020; Verity et al., 2020), whereby the IFR lies between 0.4 and 1.0 (sometimes higher depending on the cluster) and the CFR is always higher. 
The psychological and psychiatric consequences of pandemics are in general dramatic (Huremović, 2019). There have been persistent negative effects years after SARS-CoV-1 epidemics (Lee et al., 2007). The stressors and psychological impact of quarantine have been well investigated (Brooks et al., 2020). A narrative synthesis of 24 investigations revealed that psychological responses in the general population after the COVID-19 pandemic began "included anxiety/fears, depression, anger, guilt, grief and loss, posttraumatic stress and stigmatisation, but also a greater sense of empowerment and compassion towards others" (Chew et al., 2020). The prevalence of psychiatric disorders since the COVID-19 pandemic began has been investigated in several countries, with a wide range of figures (Xiong et al., 2020). In an online survey in Cyprus ( $N=1642$ adults), $48 \%$ reported significant financial concerns, $66.7 \%$ significant changes in their quality of life, $48 \%$ mild ( $9.2 \%$ moderate-severe) depressive symptoms, and $41 \%$ mild (23.1 moderate-severe) anxiety symptoms (Solomou \& Constantinidou, 2020). In a large cross-sectional study in February/March 2020 in 34 Chinese provinces ( $N=56,679)$, $27.9 \%$ had symptoms of depression, $31.6 \%$ symptoms of anxiety, 29.2\% insomnia, and $24.4 \%$ symptoms of acute stress (Shi et al., 2020). Morbidity and Mortality Weekly Report from the U.S. Department of Health and Human Services published in August 2020 the results of a June 2020 survey $(N=5412)$ : "overall, $40.9 \%$ of respondents reported at least one adverse mental or behavioural health condition, including symptoms of anxiety or depressive disorder (30.9\%), symptoms of a trauma- and stressor related disorder related to the pandemic (26.3\%), and having started or increased substance use to cope with stress or emotions related to COVID-19 (13.3\%). The percentage of respondents who reported having seriously considered suicide in the 30 days before completing the survey amounted 10.7\%"; these figures are significantly higher than one year before (Czeisler et al., 2020). The prevalence of psychiatric symptoms or disorders among medical staff is higher than in the general population (Lai et al., 2020). A Romanian survey $(N=115)$ reported that medical workers refocused more frequently than the general population on planning and positive reappraisal as coping mechanisms and that there are no differences in disease perception, stress levels, and coping mechanisms between persons that worked in COVID-19 wards and those working in non-COVID-19 services (Man et al., 2020).

Psychological and psychiatric research about the impact of the COVID-19 pandemic has focused on the prevalence of adverse economic and psychosocial consequences, the psychological strain and prevalence of psychiatric disorders, and the quality of life for the general population as well as for specific groups such as medical staff, people in quarantine, COVID-19 survivors, relatives, or residents in institutions. There are investigations about protective and straining factors as well as coping mechanisms, but little has been investigated about changes in attitudes or value-based behavior, although the global threat due to pandemics shakes the self-evidence of everyday life and makes personal perspectives and the future of our societies insecure. Nevertheless, "meaning matters" since some investigations, "reinforce past findings that meaning in life can effectively 
buffer against the impact of negative life events such as the COVID-19 pandemic" (Humphrey \& Vari, 2021). An important Italian survey $(\mathrm{N}=21,344)$ demonstrates by means of structural equation modelling, that "the presence of any stressful event was associated with depressive and anxiety symptoms and perceived stress. Resilience mediated the effects of stressful COVID-19-related events on depressive and anxiety symptoms and perceived stress. The moderated mediation analysis revealed that age moderated the mediation effect of resilience between the presence of a stressful event and the selected outcomes" (Rossi et al., 2021); therefore, increasing age means a protective factor with respect to mental health outcomes during lockdown measures. It can be assumed that an increasing age empowers maturity facing adversity mediated by more consolidated positive life attitudes, with the exception of multimorbid and cognitively impaired old people.

As pointed out in the introductory section, the aim of this investigation is to assess the impact of lockdown-as a response to the new threat due to pandemics-on life attitudes and on reflecting dimensions about the real finiteness of life. Due to the available personality data, differences have been controlled by important personality variables as traits, socio-demographic variables, attribution style and self-efficacy.

\section{Method}

\subsection{Study Design and Objectives}

This prospective, naturalistic, and comparative study began in November 2019 with the aim to examine the life attitudes and the pattern of confrontation with death of young adults (18 - 25 years old) and middle-aged adults (40 - 55 years old) from the general population. Enrolled young adults are students of different faculties, undergoing vocational training, and members of local associations. Middle-aged adults are working in two different companies in different positions according to graduation. Participants were informed about and consented to participate this investigation. Data were collected under pseudonymisation, and statistical calculations were conducted anonymously.

In mid-March 2020, a COVID-19 lockdown was imposed in Germany, similar to other European countries. We immediately modified the study design and assessed the influence of the COVID-19 lockdown on value-based responses to the two investigated questionnaires. We defined the compared samples as "before lockdown" (1 November 2019 until 21 March 2020) and "during lockdown" (21 March until 15 June 2020). The primary target variables/outcomes are differences in dimensions corresponding to the two implemented value-based questionnaires: Anticipatory Farewell to Existence Questionnaire (AFEQT) and Life Attitudes Profile-Revised (LAP-R). The subsamples contain different individuals; therefore, control variables are crucial when both of the subsamples have to be compared.

The objectives of the study were to answer the following questions:

1) Are there differences in confrontation with death and in awareness of life attitudes between individuals assessed before and during the COVID-19 lockdown? 
2) Are there differences during lockdown between individuals who are not influenced in their awareness by pandemics and individuals who are moderately or strong influenced by pandemics?

\subsection{Assessed Variables}

The primary target variables are the dimensions of the AFEQT and of LAP-R. The control variables are the socio-demographic, medical, personality, and resource variables. Specifically, these variables include:

Socio-demographic variables: age, sex, education (dichotomous: elementary and secondary schooling versus high school), migration background, parenthood, living in a couple (all of them dichotomous) (see Table 1);

Table 1. Descriptive statistics of the whole sample and compared subsamples.

\begin{tabular}{|c|c|c|c|c|c|c|c|c|c|c|c|c|}
\hline & \multicolumn{3}{|c|}{$\begin{array}{l}\text { Whole sample } \\
\qquad(N=302)\end{array}$} & \multicolumn{3}{|c|}{$\begin{array}{l}\text { Before COVID-19 } \\
\text { lockdown }(n=116)\end{array}$} & \multicolumn{3}{|c|}{$\begin{array}{l}\text { During COVID-19 } \\
\text { lockdown }(n=186)\end{array}$} & \multicolumn{3}{|c|}{ Differences } \\
\hline & $M(S D)$ or $\%$ & $M d n$ & S-W & $\begin{array}{l}M(S D) \\
\quad \text { or } \%\end{array}$ & $M d n$ & S-W & $\begin{array}{l}M(S D) \\
\quad \text { or } \%\end{array}$ & $M d n$ & S-W & $\begin{array}{c}z, t, \text { or } \\
\chi^{2}\end{array}$ & $p$ & $d$ or $\mathrm{V}$ \\
\hline Age & $34.5(14.5)$ & 25 & $<0.001$ & $29.6(12.7)$ & 23 & $<0.001$ & $37.6(14.8)$ & 44 & $<0.001$ & 4.94 & $<0.001$ & 0.57 \\
\hline Gender (\% women) & $64.1 \%$ & & & $61.7 \%$ & & & $65.9 \%$ & & & 0.54 & n.s. & 0.04 \\
\hline Education (\% high school) & $61.3 \%$ & & & $56.0 \%$ & & & $64.5 \%$ & & & 2.16 & n.s. & 0.08 \\
\hline Migration background & $12.1 \%$ & & & $15.8 \%$ & & & $9.8 \%$ & & & 2.39 & n.s. & 0.09 \\
\hline Parenthood & $45.5 \%$ & & & $36.2 \%$ & & & $51.3 \%$ & & & 6.59 & 0.010 & 0.15 \\
\hline Currently living in couple & $65.8 \%$ & & & $62.9 \%$ & & & $67.6 \%$ & & & 0.68 & n.s. & 0.05 \\
\hline Illness requiring treatment & $34.8 \%$ & & & $34.9 \%$ & & & $34.8 \%$ & & & $<0.001$ & n.s. & 0.001 \\
\hline Past hospitalization & $86.1 \%$ & & & $85.2 \%$ & & & $86.6 \%$ & & & 0.11 & n.s. & 0.02 \\
\hline Past psychiatric hospitalization & $7.0 \%$ & & & $9.5 \%$ & & & $5.4 \%$ & & & 1.82 & n.s. & 0.08 \\
\hline Past psychiatric treatment & $20.2 \%$ & & & $20.7 \%$ & & & $19.9 \%$ & & & 0.03 & n.s. & 0.01 \\
\hline Current psychopharmacology & $4.0 \%$ & & & $6.0 \%$ & & & $2.7 \%$ & & & 2.04 & n.s. & 0.08 \\
\hline BFI-neuroticism ${ }^{\star}$ & $2.86(0.65)$ & 3.0 & n.s. & $2.83(0.66)$ & 3.0 & n.s. & $2.89(0.65)$ & 3.0 & n.s. & 0.75 & n.s. & 0.09 \\
\hline BFI-extraversion* & $3.20(0.72)$ & 3.0 & n.s. & $3.21(0.76)$ & 3.0 & n.s. & $3.19(0.70)$ & 3.0 & n.s. & 0.15 & n.s. & 0.02 \\
\hline BFI-openness* & $3.16(0.74)$ & 3.5 & 0.001 & $3.11(0.73)$ & 3.2 & n.s. & $3.20(0.75)$ & 3.2 & 0.004 & 1.03 & n.s. & 0.12 \\
\hline BFI-agreeableness* & $3.43(0.74)$ & 3.2 & n.s. & $3.40(0.74)$ & 3.5 & n.s. & $3.44(0.62)$ & 3.5 & n.s. & 0.48 & n.s. & 0.06 \\
\hline BFI-consciousness ${ }^{\star}$ & $3.07(0.65)$ & 3.0 & n.s. & $2.95(0.64)$ & 2.9 & n.s. & $3.14(0.65)$ & 3.1 & n.s. & 2.39 & 0.017 & 0.28 \\
\hline Internal attribution style ${ }^{\star *}$ & $7.94(1.44)$ & 8.0 & $<0.001$ & $8.10(1.24)$ & 8.0 & $<0.001$ & $7.84(1.55)$ & 8.0 & $<0.001$ & 1.02 & n.s. & 0.18 \\
\hline External attribution style ${ }^{* *}$ & $4.72(1.46)$ & 5.0 & 0.001 & $4.89(1.49)$ & 5.0 & 0.038 & $4.62(1.44)$ & 5.0 & 0.001 & 1.16 & n.s. & 0.18 \\
\hline Self-efficacy ${ }^{\star}$ & $17.6(2.6)$ & 18.0 & n.s. & $17.4(2.6)$ & 18.0 & n.s. & $17.8(2.6)$ & 18.0 & n.s. & 1.28 & n.s. & 0.15 \\
\hline
\end{tabular}

Note. $n=($ sub) sample size; $M=$ mean; $S D=$ standard deviation; $M d n=$ median; $\mathrm{S}-\mathrm{W}=$ Shapiro-Wilk test of normality for metric variables (n.s. $=$ normal distribution of values for the variable); $z, t$, or $\chi^{2}=$ values for $z, t$, or $\chi^{2}$ statistics; $d=$ Cohen's d, effect size of differences for metric variables; $\mathrm{V}=$ Cramer's $\mathrm{V}$, effect size for categorical variables; BFI = Big Five Inventory-10 items. ${ }^{\star}=$ $t$-test; ${ }^{\star *}=$ Mann-Whitney $U$ test; n.s. $=$ not statistically significant at the 0.05 level. 
Medical variables: currently suffering from an illness requiring treatment; past hospitalisation due to a physical disease, psychiatric condition, or psychiatric treatment; and current treatment with psychotropic drugs (all of them dichotomous) (see Table 1);

Personality: the dimensions of the Big Five Inventory-10 (BFI-10) (see Table $1)$;

Personal resources: self-efficacy by means of the General Self-Efficacy Scale (GSW-6) and attributions by means of Internal-External-Control-Belief (IE-4) (see Table 1, References below);

Confrontation with death: assessment by means of a questionnaire developed by the first author (AEFQT) consisting of five dimensions: self-transcendence, the expiration of one's existence, altruistic preoccupation, reconciliation with one's existence, and struggle for acceptance of finiteness (see Table 2);

Life attitudes: assessment by means of the LAP-R, which comprises six dimensions and two indices (see Table 2).

\subsection{Psychometric Tools}

GSW-6: The original German version (Generelle Selbstwirksamkeitsskala) measures the expectation of competence from a positive point of view, namely the trust in oneself to master difficult situations. The scale consists of six items on a Likert scale of $1-4$. The total score ranges from 4 to 24 (Romppel et al., 2013).

IE-4: The original German version (Skala Internale-Externale-Kontrollattribution) assesses the conviction to be able to determine and control the course of one's life. This brief scale consists of four items on a Likert scale of $1-5$, distributed on two subscales (internal/external) (Kovaleva et al., 2012).

BFI-10: This internationally recognized personality scale is based on a dimensional and not a categorical concept of personality. This inventory encompasses five dimensions (neuroticism, extraversion, openness, agreeableness, and consciousness) assessed by 10 questions, two per dimension (one of them with a reversed polarity), each on a Likert scale of 1 - 5 (Rammstedt, 2007).

AFEQT: This questionnaire is a formative rather than a reflective measurement model; therefore, the justification of the model is based on the coherence of the underlying anthropological construct and less on confirmatory factor analysis. It consists of 51 questions, 10/11 per dimension. Each dimension comprises two partially overlapping factors (see Table 2). This questionnaire has been used to assess confrontation with death in dying people and other samples; it has shown an acceptable reliability and criterion validity (Valdés-Stauber et al., 2021).

LAP-R: This questionnaire is value based and rooted in the concept of "meaning in life" and in the logotherapy by Viktor Frankl. This questionnaire has been validated in several settings. It consists of 48 questions corresponding to six dimensions (see Table 2). This study implements the German version by Mehnert et al. (Mehnert et al., 2007). 
Table 2. Differences in the dimensions of the anticipatory farewell to existence questionnaire and life attitudes profile-revised between individuals surveyed before and during the COVID-19 lockdown.

\begin{tabular}{|c|c|c|c|c|c|c|c|c|c|c|c|c|}
\hline & \multicolumn{3}{|c|}{$\begin{array}{l}\text { Whole sample } \\
\qquad(N=302)\end{array}$} & \multicolumn{3}{|c|}{$\begin{array}{l}\text { Before COVID-19 } \\
\text { lockdown }(n=116)\end{array}$} & \multicolumn{3}{|c|}{$\begin{array}{l}\text { During COVID-19 } \\
\text { lockdown }(n=186)\end{array}$} & \multicolumn{3}{|c|}{ Differences } \\
\hline & $M(S D)$ & $M d n$ & S-W & $M(S D)$ & $M d n$ & S-W & $M(S D)$ & $M d n$ & S-W & $z$ & $p$ & $d$ \\
\hline \multicolumn{13}{|l|}{ Anticipatory farewell to existence } \\
\hline Permanence & $2.69(0.77)$ & 2.6 & 0.002 & $2.71(0.76)$ & 2.6 & n.s. & $2.67(0.78)$ & 2.8 & 0.001 & 0.007 & n.s. & 0.04 \\
\hline Metaphysical rise & $2.48(0.80)$ & 2.4 & 0.023 & $2.33(0.80)$ & 2.4 & 0.045 & $2.57(0.79)$ & 2.6 & n.s. & 2.45 & 0.014 & 0.30 \\
\hline D I: Self-transcendence & $2.58(0.64)$ & 2.6 & n.s. & $2.51(0.67)$ & 2.5 & n.s. & $2.62(0.61)$ & 2.6 & 0.004 & 1.72 & n.s. & 0.18 \\
\hline Conclusion & $3.11(1.99)$ & 3.2 & $<0.001$ & $3.04(0.68)$ & 3.0 & 0.001 & $3.16(0.59)$ & 3.2 & 0.006 & 1.37 & n.s. & 0.20 \\
\hline Farewell & $1.99(0.57)$ & 2.0 & n.s. & $2.02(0.57)$ & 2.0 & n.s. & $1.97(0.57)$ & 2.0 & n.s. & 0.37 & n.s. & 0.09 \\
\hline $\begin{array}{r}\text { D II: The expiration of own } \\
\text { existence time }\end{array}$ & $2.55(0.52)$ & 2.6 & 0.039 & $2.53(0.54)$ & 2.6 & n.s. & $2.56(0.50)$ & 2.6 & n.s. & 0.56 & n.s. & 0.07 \\
\hline Bequest & $3.20(0.56)$ & 3.2 & $<0.001$ & $3.13(0.58)$ & 3.2 & $<0.001$ & $3.25(0.55)$ & 3.4 & $<0.001$ & 1.98 & 0.047 & 0.22 \\
\hline Charity & $2.73(0.61)$ & 2.8 & n.s. & $2.68(0.57)$ & 2.6 & n.s. & $2.76(0.64)$ & 2.8 & n.s. & 1.44 & n.s. & 0.13 \\
\hline D III: Altruistic preoccupation & $2.97(0.50)$ & 3.0 & $<0.001$ & $2.90(0.49)$ & 2.9 & n.s. & $3.01(0.50)$ & 3.1 & $<0.001$ & 2.13 & 0.032 & 0.21 \\
\hline Fulfilment of existence & $3.04(0.66)$ & 3.2 & $<0.001$ & $2.99(0.67)$ & 3.0 & $<0.001$ & $3.07(0.64)$ & 3.2 & $<0.001$ & 1.08 & n.s. & 0.11 \\
\hline Harmony & $2.90(0.70)$ & 3.0 & $<0.001$ & $2.90(0.71)$ & 3.0 & $<0.001$ & $2.95(0.66)$ & 3.0 & $<0.001$ & 1.05 & n.s. & 0.11 \\
\hline $\begin{array}{r}\text { D IV: Reconciliation with own } \\
\text { existence }\end{array}$ & $3.00(0.64)$ & 3.1 & $<0.001$ & $2.95(0.66)$ & 3.1 & $<0.001$ & $3.03(0.62)$ & 3.1 & $<0.001$ & 1.17 & n.s. & 0.12 \\
\hline Resistance & $2.22(0.55)$ & 2.2 & n.s. & $2.22(0.50)$ & 2.2 & n.s. & $2.21(0.58)$ & 2.2 & n.s. & 0.50 & n.s. & 0.01 \\
\hline Acceptance & $2.60(0.64)$ & 2.6 & n.s. & $2.57(0.67)$ & 2.6 & n.s. & $2.62(0.62)$ & 2.6 & 0.031 & 0.31 & n.s. & 0.07 \\
\hline D V: Struggle for acceptance & $2.42(0.45)$ & 2.4 & 0.004 & $2.41(0.48)$ & 2.4 & n.s. & $2.42(0.43)$ & 2.4 & 0.002 & 0.10 & n.s. & 0.01 \\
\hline \multicolumn{13}{|l|}{ Life attitudes profile-revised } \\
\hline Life purpose & $4.07(0.93)$ & 4.1 & $<0.001$ & $3.98(0.90)$ & 4.1 & $<0.001$ & $4.13(0.94)$ & 4.2 & $<0.001$ & 1.65 & n.s. & 0.17 \\
\hline Coherence & $3.67(1.09)$ & 3.7 & 0.024 & $3.50(0.97)$ & 3.5 & n.s. & $3.78(1.14)$ & 3.8 & 0.004 & 2.70 & 0.007 & 0.26 \\
\hline Choice/Responsibleness & $3.81(0.94)$ & 3.9 & 0.019 & $3.91(0.87)$ & 4.0 & n.s. & $3.76(0.98)$ & 3.7 & 0.017 & 0.95 & n.s. & 0.15 \\
\hline Death acceptance & $3.71(1.10)$ & 3.7 & n.s. & $3.47(1.18)$ & 3.6 & n.s. & $3.86(1.02)$ & 3.8 & n.s. & 2.91 & 0.003 & 0.13 \\
\hline Existential vacuum & $2.43(0.95)$ & 2.4 & $<0.001$ & $2.52(0.96)$ & 2.4 & 0.001 & $2.38(0.94)$ & 2.4 & 0.009 & 1.08 & n.s. & 0.15 \\
\hline Goal seeking & $3.46(0.97)$ & 3.4 & n.s. & $3.38(0.98)$ & 3.4 & n.s. & $3.51(0.96)$ & 3.5 & n.s. & 1.07 & n.s. & 0.13 \\
\hline Personal meaning index & $7.75(1.86)$ & 7.9 & $<0.001$ & $7.47(3.51)$ & 7.6 & 0.005 & $7.91(1.91)$ & 8.1 & 0.002 & 2.34 & 0.019 & 0.24 \\
\hline Existential transcendence & $9.37(3.59)$ & 9.6 & 0.015 & $8.94(3.51)$ & 9.3 & n.s. & $9.64(3.62)$ & 10.0 & n.s. & 1.78 & n.s. & 0.19 \\
\hline
\end{tabular}

Note. $n=$ (sub) sample size; $M=$ mean; $S D=$ standard deviation; $M d n=$ median; $\mathrm{S}-\mathrm{W}=$ Shapiro-Wilk test of normality for metric variables (n.s. = normal distribution of values for the variable); $z=$ value for $z$ statistic; $d=$ Cohen's d, effect size of differences for metric variables; $\mathrm{D}=$ dimension. n.s. = not statistically significant at 0.05 level.

\subsection{Statistics}

We assessed all metric variables by the mean, standard deviation, and median. We used the Shapiro-Wilk test to determine whether the variables were normally distributed and thus whether to employ parametric or non-parametric tests to compare variables before and during lockdown. 
We initially investigated the first objective by means of bivariate tests (unpaired $t$-tests for normally distributed variables and Mann-Whitney $U$ tests for non-normally distributed variables), considering effect sizes (Cohen's $d$ ). We then analyzed the data using linear multivariate models, considering 16 control variables and implementing robust estimators. The share of the explained variance of the dependent variable is given by the determination coefficient $\left(R^{2}\right)$.

We first assessed the second objective by means of linear multivariate regression models with robust estimators; the group variable (three compared subsamples on a scale between 0 and 10) has three categories: no influence (0), low influence ( 1 - 4), and high influence (5 - 8) based on responses about one's awareness of pandemics. We then assessed this objective using three different multinomial regression models. The reason for choosing multinomial regression models was that the dependent variable (level of influence of pandemics on responses) displays three categories. We evaluated associations by means of relative risk ratios (RRRs); the RRR of a coefficient indicates the likelihood to fall in the index group compared with the base-outcome group; $\mathrm{RRR}<1$ indicates a higher likelihood to fall in the base-outcome group when the variable increases (when dichotomous, then value of variable $=1$ vs 0 ); inversely, RRR $>1$ indicates a higher likelihood to fall in the index group compared with the base-outcome group when the variable increases.

We performed all calculations using the statistical package Stata MP 13.

This investigation was approved by the Ethics Committee of the University of Ulm (registration number 02/19). Written informed consent in German was obtained from all participants.

\section{Results}

There are no statistically significant differences between the subsample assessed prior to and during the lockdown with regard to all assessed socio-demographic variables (except age and parenthood), medical variables, personality dimensions (except consciousness), self-efficacy, and internal/external attribution styles. The subsample assessed during the COVID-19 pandemic is on average 8 years older (with a left-skewed distribution, whereas the subsample before lockdown displays a right-skewed distribution), there are more parents, and they display on average higher levels of consciousness (Table 1).

Regarding the AFEQT dimensions and factors, the subsample assessed during the COVID-19 lockdown displays significantly higher average scores for the factor "metaphysical rise" and for the dimension "altruistic preoccupation," primarily fed by the factor "bequest" (Table 2). In multivariate regression models, these differences disappear (Table 3 ). The effect size are moderate $(<0.30)$. With respect to the LAP-R dimensions, the subsample assessed during lockdown displays on average higher scores for the dimensions "coherence" and "death acceptance" as well as the "personal meaning index" (PMI). In linear multivariate regression models, the differences for "death acceptance" are reinforced; in addition, there 
Table 3. Multivariate regression models for dimensions of anticipatory farewell to existence and life attitudes profile-revised based on robust estimators.

\begin{tabular}{|c|c|c|c|c|c|c|c|c|c|c|c|c|c|}
\hline & \multicolumn{5}{|c|}{ Anticipatory farewell to existence } & \multicolumn{8}{|c|}{ Life attitudes profile-revised } \\
\hline & D I & D II & D III & D IV & $\mathrm{D} \mathrm{V}$ & LP & $\mathrm{CO}$ & CR & DA & EV & GS & PMI & ET \\
\hline & Coeff ${ }^{p}$ & Coeff ${ }^{p}$ & Coeff ${ }^{p}$ & Coeff ${ }^{p}$ & Coeff ${ }^{p}$ & Coeff ${ }^{p}$ & Coeff ${ }^{p}$ & Coeff ${ }^{p}$ & Coeff ${ }^{p}$ & Coeff ${ }^{p}$ & Coeff ${ }^{p}$ & Coeff ${ }^{p}$ & Coeff ${ }^{p}$ \\
\hline Prior/during lockdown & n.s. & n.s. & n.s. & n.s. & n.s. & n.s. & n.s. & & $0.53^{* * *}$ & n.s. & $0.31^{* *}$ & n.s. & n.s. \\
\hline Age & $0.01^{\star}$ & $0.01^{* *}$ & n.s. & $0.01^{\star * *}$ & $-0.01^{\star}$ & $0.01^{*}$ & $0.03^{* * *}$ & $-0.01^{\star}$ & n.s. & $-0.02^{\star * *}$ & $0.02^{* * *}$ & $0.04^{* * *}$ & $0.07^{* * *}$ \\
\hline $\operatorname{Sex}(1=$ men $)$ & $-0.16^{\star *}$ & n.s. & n.s. & $-0.4^{* * *}$ & n.s. & $-0.4^{\star \star \star}$ & $-0.29^{\star}$ & $-0.22^{\star}$ & $0.40^{\star *}$ & $0.44^{\star * *}$ & $0.28^{\star \star}$ & $-0.67^{\star *}$ & $-10.21^{\star *}$ \\
\hline Education ( 1 = high school) & n.s. & n.s. & n.s. & n.s. & $-0.14^{*}$ & n.s. & n.s. & n.s. & n.s. & n.s. & n.s. & n.s. & n.s. \\
\hline Partnership ( $1=$ yes $)$ & n.s. & n.s. & n.s. & n.s. & n.s. & n.s. & n.s. & n.s. & n.s. & n.s. & n.s. & n.s. & n.s. \\
\hline $\begin{array}{l}\text { Illness requiring treatment } \\
(1=\text { yes })\end{array}$ & n.s. & n.s. & n.s. & n.s. & n.s. & n.s. & n.s. & n.s. & n.s. & n.s. & n.s. & n.s. & n.s. \\
\hline Past hospitalization ( 1 = yes) & n.s. & n.s. & n.s. & n.s. & n.s. & n.s. & n.s. & n.s. & n.s. & n.s. & n.s. & n.s. & n.s. \\
\hline $\begin{array}{l}\text { Past psychiatric treatment } \\
(1=\text { yes })\end{array}$ & n.s. & n.s. & n.s. & $-0.23^{\star}$ & n.s. & n.s. & n.s. & n.s. & n.s. & $0.32^{\star}$ & n.s. & n.s. & n.s. \\
\hline $\begin{array}{l}\text { Current psychopharmacology } \\
\text { (1=yes) }\end{array}$ & n.s. & n.s. & n.s. & n.s. & n.s. & n.s. & n.s. & n.s. & n.s. & n.s. & n.s. & n.s. & n.s. \\
\hline BFI-neuroticism & $-0.14^{*}$ & n.s. & n.s. & n.s. & $-0.13^{\star *}$ & n.s. & n.s. & n.s. & n.s. & n.s. & n.s. & n.s. & n.s. \\
\hline BFI-extraversion & n.s. & n.s. & n.s. & n.s. & n.s. & n.s. & n.s. & n.s. & n.s. & n.s. & n.s. & n.s. & n.s. \\
\hline BFI-openness & n.s. & n.s. & n.s. & n.s. & n.s. & n.s. & n.s. & n.s. & n.s. & n.s. & n.s. & n.s. & n.s. \\
\hline BFI-agreeableness & $0.23^{* *}$ & n.s. & $0.19^{\star *}$ & n.s. & n.s. & n.s. & n.s. & n.s. & n.s. & n.s. & $.21^{\star}$ & n.s. & n.s. \\
\hline BFI-consciousness & n.s. & n.s. & $-0.12^{\star}$ & n.s. & n.s. & n.s. & n.s. & n.s. & n.s. & $0.35^{\star \star *}$ & n.s. & n.s. & $-1.11^{\star *}$ \\
\hline Self-efficacy & $0.05^{\star *}$ & $0.06^{* * *}$ & $0.05^{\star * *}$ & $0.09^{\star * *}$ & n.s. & $0.10^{\star * *}$ & $0.14^{\star * *}$ & $0.06^{* *}$ & n.s. & $-0.06^{\star *}$ & n.s. & $0.24^{\star * *}$ & $0.34^{* * *}$ \\
\hline Internal attribution style & n.s. & n.s. & n.s. & n.s. & n.s. & $0.17^{\star * *}$ & n.s. & $0.32^{\star * *}$ & n.s. & $0.09^{*}$ & n.s. & $0.18^{*}$ & $0.50^{* *}$ \\
\hline External attribution style & n.s. & n.s. & n.s. & $-.09^{\star *}$ & n.s. & n.s. & n.s. & $-0.11^{\star *}$ & n.s. & n.s. & n.s. & n.s. & $-0.43^{\star *}$ \\
\hline$N$ & 276 & 276 & 276 & 276 & 276 & 276 & 276 & 276 & 276 & 276 & 276 & 276 & 276 \\
\hline$F$ or $p$ & $6.97^{\star * *}$ & $4.37^{\star * *}$ & $8.33^{* * *}$ & $10.4^{\star * *}$ & $2.56^{* * *}$ & $8.7^{\star \star *}$ & $8.75^{\star * *}$ & $24.1^{\star * \star}$ & $2.65^{\star * *}$ & $13.3^{\star * *}$ & $9.3^{* * *}$ & $3.2^{\star * *}$ & $14.1^{\star * *}$ \\
\hline $\mathrm{R}^{2}$ & 0.25 & 0.21 & 0.35 & 0.41 & 0.12 & 0.40 & 0.34 & 0.51 & 0.15 & 0.44 & 0.34 & 0.39 & 0.43 \\
\hline
\end{tabular}

Note. Comparison of subsamples before and during the COVID-19 lockdown. $\mathrm{D}=$ dimension of the AFEQT-questionnaire; LP = life purpose; $\mathrm{CO}=$ coherence; $\mathrm{CR}=$ choice/responsibleness; $\mathrm{DA}=$ death acceptance; $\mathrm{EV}=$ existential vacuum; $\mathrm{GS}=$ goal seeking; $\mathrm{PMI}=$ personal meaning index; ET = existential transcendence; BFI = Big Five Inventory-10 items; Coeff = robust estimator; $p=$ statistical significance; $N=$ sample size in model; $F=$ value of $F$ statistic; $R^{2}=$ determination coefficient: share of variance of dependent variable explained by model. ${ }^{*}<0.05 ;{ }^{* *}<0.01:^{* * *}<0.001$.

are higher scores for the dimension "goal seeking" for the subsample during lockdown. The models are statistically significant and explain between $15 \%$ and $51 \%$ of the variance of assessed dimensions (Table 3).

Independently of group differences, age, gender (more women), higher selfefficacy, and internal attribution style are associated with higher scores of assessed value-based dimensions, except for "existential vacuum" because it was inversely conceived relative to the other dimensions (Table 3). These results are replicated in alternative multivariate models when only considering the group assessed 
during the COVID-19 pandemic, especially for age, self-efficacy, and internal attribution style (Table 4).

We investigated whether some variables are associated with an incremental influence of pandemics on responses, considering three categories of influence and "no influence" as the base outcome. In the first model-including sociodemographic, medical, personality, and resource variables-to suffer from a current illness requiring treatment increases the likelihood to be assigned to the

Table 4. Multivariate regression models for dimensions of anticipatory farewell to existence and life attitudes profile-revised based on robust estimators.

\begin{tabular}{|c|c|c|c|c|c|c|c|c|c|c|c|c|c|}
\hline & \multicolumn{5}{|c|}{ Anticipatory farewell to existence } & \multicolumn{8}{|c|}{ Life attitudes profile-revised (LAP-R) } \\
\hline & D I & D II & D III & D IV & D V & LP & $\mathrm{CO}$ & CR & DA & EV & GS & PMI & ET \\
\hline Base outcome (no influence) & Coeff $^{p}$ & Coeff $^{p}$ & Coeff $^{\mathrm{p}}$ & Coeff $^{p}$ & Coeff $^{p}$ & Coeff $^{p}$ & Coeff & Coeff & Coeff $^{\mathrm{p}}$ & Coeff & Coeff $^{p}$ & Coeff $^{p}$ & Coeff $^{p}$ \\
\hline Low influence $(1-4)$ & n.s. & n.s. & n.s. & $0.21^{*}$ & n.s. & n.s. & n.s. & n.s. & n.s. & n.s. & n.s. & n.s. & n.s. \\
\hline High influence $(5-8)$ & n.s. & n.s. & n.s. & n.s. & n.s. & n.s. & n.s. & n.s. & n.s. & n.s. & $0.55^{*}$ & n.s. & n.s. \\
\hline Age & $0.02^{* * *}$ & $0.01^{* * *}$ & $0.007^{*}$ & $0.01^{* *}$ & n.s. & $0.01^{*}$ & $0.04^{* * *}$ & n.s. & n.s. & $-0.02^{\star * *}$ & $-0.02^{\star * *}$ & $0.05^{* * *}$ & $0.10^{\star * *}$ \\
\hline $\operatorname{Sex}(1=\operatorname{men})$ & n.s. & n.s. & n.s. & n.s. & n.s. & n.s. & n.s. & n.s. & n.s. & $0.43^{* *}$ & n.s. & n.s. & $-0.99^{*}$ \\
\hline Education $(1=$ high school $)$ & n.s. & n.s. & n.s. & n.s. & $-0.19^{*}$ & n.s. & n.s. & n.s. & n.s. & n.s. & n.s. & n.s. & n.s. \\
\hline Partnership $(1=$ yes $)$ & n.s. & n.s. & n.s. & n.s. & n.s. & n.s. & n.s. & n.s. & n.s. & $-0.33^{*}$ & n.s. & n.s. & n.s. \\
\hline $\begin{array}{l}\text { Illness requiring treatment } \\
(1=\text { yes })\end{array}$ & n.s. & n.s. & n.s. & n.s. & n.s. & n.s. & n.s. & n.s. & n.s. & n.s. & n.s. & n.s. & n.s. \\
\hline Past hospitalisation $(1=$ yes $)$ & n.s. & n.s. & n.s. & n.s. & n.s. & n.s. & n.s. & n.s. & $-0.52^{\star}$ & n.s. & n.s. & n.s. & n.s. \\
\hline $\begin{array}{l}\text { Past psychiatric treatment } \\
(1=\text { yes })\end{array}$ & n.s. & $0.23^{*}$ & n.s. & $-0.27^{\star}$ & n.s. & n.s. & n.s. & n.s. & $-0.48^{\star}$ & $0.42^{*}$ & n.s. & n.s. & n.s. \\
\hline $\begin{array}{l}\text { Current psychopharmacology } \\
\text { (1= yes) }\end{array}$ & n.s. & n.s. & n.s. & n.s. & n.s. & n.s. & n.s. & n.s. & n.s. & n.s. & n.s. & n.s. & n.s. \\
\hline BFI-neuroticism & $-0.19^{*}$ & n.s. & n.s. & n.s. & n.s. & n.s. & n.s. & n.s. & n.s. & n.s. & n.s. & n.s. & n.s. \\
\hline BFI-extraversion & n.s. & n.s. & n.s. & n.s. & n.s. & n.s. & n.s. & n.s. & n.s. & n.s. & n.s. & n.s. & n.s. \\
\hline BFI-openness & n.s. & n.s. & n.s. & n.s. & n.s. & n.s. & n.s. & n.s. & n.s. & n.s. & n.s. & n.s. & n.s. \\
\hline BFI-agreeableness & $0.30^{* *}$ & n.s. & $0.25^{*}$ & n.s. & n.s. & n.s. & n.s. & n.s. & n.s. & n.s. & n.s. & n.s. & n.s. \\
\hline BFI-consciousness & n.s. & n.s. & n.s. & n.s. & n.s. & n.s. & n.s. & n.s. & n.s. & $0.31^{*}$ & n.s. & n.s. & n.s. \\
\hline Self-efficacy & n.s. & $0.05^{* *}$ & $0.06^{* *}$ & $0.09^{* * *}$ & n.s. & n.s. & $0.17^{* * *}$ & $0.06^{*}$ & n.s. & $-0.09^{\star *}$ & n.s. & $0.27^{* * *}$ & $0.36^{\star *}$ \\
\hline Internal attribution style & $0.08^{*}$ & n.s. & n.s. & n.s. & n.s. & n.s. & n.s. & $0.36^{* * *}$ & n.s. & n.s. & n.s. & n.s. & $0.66^{* *}$ \\
\hline External attribution style & n.s. & n.s. & n.s. & n.s. & n.s. & n.s. & n.s. & n.s. & n.s. & n.s. & n.s. & n.s. & n.s. \\
\hline$N$ & 160 & 160 & 160 & 160 & 160 & 160 & 160 & 160 & 160 & 160 & 160 & 160 & 160 \\
\hline$F$ or $p$ & $4.17^{* * *}$ & $3.02^{* *}$ & $5.08^{* *}$ & $7.19^{* * *}$ & $1.97^{\star}$ & $6.23^{* * *}$ & $5.70^{* * *}$ & $14.7^{* * *}$ & n.s. & $10.6^{* * *}$ & $5.86^{* * *}$ & $6.07^{* * *}$ & $8.46^{* * *}$ \\
\hline$R^{2}$ & 0.30 & 0.20 & 0.33 & 0.42 & 0.16 & 0.40 & 0.36 & 0.54 & 0.15 & 0.50 & 0.37 & 0.38 & 0.44 \\
\hline
\end{tabular}

Note. Within sample after lockdown due to the COVID-19 pandemic; comparison of subsamples before and during the COVID-19 lockdown. $\mathrm{D}=$ dimension of AFEQT-questionnaire; $\mathrm{LP}=$ life purpose; $\mathrm{CO}=$ coherence; $\mathrm{CR}=$ choice/responsibleness; $\mathrm{DA}=$ death acceptance; $\mathrm{EV}=$ existential vacuum; $\mathrm{GS}=$ goal seeking; $\mathrm{PMI}=$ personal meaning index; $\mathrm{ET}=$ existential transcendence; $\mathrm{BFI}=\mathrm{Big}$ Five Inventory-10 items; Coeff = robust estimator; $p=$ statistical significance; $N=$ sample size in model; $F=$ value of the $F$ statistic; $R^{2}=$ Determination coefficient: share of variance of dependent variable explained by model. ${ }^{*}<0.05 ;{ }^{* *}<0.01:{ }^{* *}<0.001$. 
group whose responses are highly influenced by a pandemic, whereas higher scores for extraversion and self-efficacy increase the likelihood to be assigned to the base-outcome group with no reported influence (Table 5). In the second

Table 5. Three different multinomial regression models in order to assess the relative risk to be assigned to a group with a higher influence of pandemics in responses.

\begin{tabular}{|c|c|c|c|c|c|c|}
\hline \multicolumn{7}{|c|}{ Base outcome: no influence of pandemic on responses } \\
\hline & \multicolumn{3}{|c|}{ Low influence } & \multicolumn{3}{|c|}{ High influence } \\
\hline & RRR & $z$ & $p$ & RRR & $z$ & $p$ \\
\hline \multicolumn{7}{|l|}{ Model I } \\
\hline Age & & & n.s. & & & n.s. \\
\hline $\operatorname{Sex}(1=\operatorname{men})$ & & & n.s. & & & n.s. \\
\hline Education ( 1 = high school) & & & n.s. & & & n.s. \\
\hline Partnership $(1=$ yes $)$ & & & n.s. & & & n.s. \\
\hline Illness requiring treatment $(1=$ yes $)$ & & & n.s. & 6.75 & 2.60 & 0.009 \\
\hline Past hospitalization $(1=$ yes $)$ & & & n.s. & & & n.s. \\
\hline Past psychiatric treatment $(1=$ yes $)$ & & & n.s. & & & n.s. \\
\hline Current psychopharmacology $(1=$ yes $)$ & & & n.s. & & & n.s. \\
\hline BFI-neuroticism & & & n.s. & & & n.s. \\
\hline BFI-extraversion & 0.26 & -2.67 & 0.008 & & & n.s. \\
\hline BFI-openness & & & n.s. & & & n.s. \\
\hline BFI-agreeableness & & & n.s. & & & n.s. \\
\hline BFI-consciousness & & & n.s. & & & n.s. \\
\hline Self-efficacy & & & n.s. & 0.69 & -2.46 & 0.014 \\
\hline Internal attribution style & & & n.s. & & & n.s. \\
\hline External attribution style & 1.37 & 1.98 & 0.048 & & & n.s. \\
\hline N/LR Chi2/Prob $>$ Chi2 & \multicolumn{6}{|c|}{$160 / 44.7 / 0.067 / 0.14$} \\
\hline \multicolumn{7}{|l|}{ Model II } \\
\hline Permanence & & & n.s. & & & n.s. \\
\hline Metaphysical rise & & & n.s. & & & n.s. \\
\hline Conclusion & & & n.s. & & & n.s. \\
\hline Farewell & & & n.s. & & & n.s. \\
\hline Bequest & & & n.s. & 14.5 & 2.88 & 0.004 \\
\hline Charity & 0.36 & -3.04 & 0.002 & 0.21 & -2.68 & 0.007 \\
\hline Fulfilment of existence & & & n.s. & 0.14 & -2.41 & 0.016 \\
\hline Harmony & & & n.s. & & & n.s. \\
\hline Resistance & & & n.s. & & & n.s. \\
\hline Acceptance & & & n.s. & & & n.s. \\
\hline$N / \mathrm{LR} \chi^{2} / p$ & & & $184 / 39.0$ & $.007 / .11$ & & \\
\hline
\end{tabular}




\section{Continued}

\section{Model III}

\begin{tabular}{|c|c|c|c|c|}
\hline Life purpose & \multicolumn{3}{|l|}{ n.s. } & n.s. \\
\hline Coherence & \multicolumn{3}{|l|}{ n.s. } & n.s. \\
\hline Choice/Responsibleness & \multicolumn{3}{|l|}{ n.s. } & n.s. \\
\hline Death acceptance & n.s. & 0.46 & -2.92 & 0.004 \\
\hline Existential vacuum & \multicolumn{3}{|l|}{ n.s. } & n.s. \\
\hline Goal seeking & \multicolumn{3}{|l|}{ n.s. } & n.s. \\
\hline$N /$ LR $\chi^{2} / p$ & \multicolumn{3}{|c|}{$184 / 21.0 / 0.050 / 0.06$} & \\
\hline
\end{tabular}

Note. The first model includes personality dimensions, resources, and control variables; the second model includes the 10 factors of the Anticipatory Farewell to Existence Questionnaire; the third model includes the 6 dimensions of Life Attitudes Profile (LAP-R). $\mathrm{BFI}=$ Big Five Inventory-10 items; $N=$ cases considered in model; RRR = relative risk ratio; $z=$ value of normalized $\mathrm{z}$-distribution; $p=$ level of significance; $\mathrm{n} . \mathrm{s} .=$ not statistically significant at 0.05 level; LR $\chi^{2}=$ Likelihood ratio of the $\chi^{2}$ statistic.

model-including the AFEQT factors (dimensions would be redundant) - higher scores for "charity" and "fulfillment of existence" are associated with a higher likelihood to be assigned to the base-outcome group, whereas higher scores for "bequest" are associated with the likelihood to be assigned to the group reporting a higher influence of a pandemic on responses (Table 5). Finally, in the third model -including the six LAP-R dimensions-higher scores of "death acceptance" are associated with a $54 \%$ greater likelihood to be assigned to the base-outcome group compared with the group reporting that a pandemic has a great influence on their responses (Table 5).

\section{Discussion}

We compared subsamples from before and during the COVID-19 lockdown in Germany using 19 variables. Only three of them showed statistical differences: the subsample during lockdown is older, has more parents, and on average displays a higher consciousness score. After a Bonferroni correction $\left(p^{\star}<0.002\right)$ only "age" remains statistically different. Particularly relevant is the lack of differences regarding medical and psychiatric history, personality dimensions, and the level of self-efficacy and attribution style.

The most relevant result of this study is the statistically significant change in some value-based dimensions. We compared both groups by means of the five dimensions and 10 factors of the AFEQT developed by the first author and implemented in prior research (Valdés-Stauber et al., 2021; Stabenow, 2021) as well as by the German version of the LAP-R, consisting of six dimensions and two indices. In bivariate tests, the factors "metaphysical rise" and "bequest" as well as the dimension "altruistic preoccupation" scored significantly higher in the subsample during lockdown, indicating a tendency to consider others and to enhance self-transcendence. In the LAP-R, the dimensions "coherence" and "death 
acceptance" scored significantly higher during lockdown, indicating an increasing awareness and acceptance of oneself, others, and life as well as to accept death as a part of life. In the next step, we compared both subsamples using linear multivariate analyses, considering 16 control variables. As expected, the differences become smaller; nevertheless, the differences between before and during the lockdown for the dimension "death acceptance" become even stronger and "goal seeking" becomes significant. These results indicate that lockdown conditions lead to a more intensive awareness about the mortal condition and the urge to reappraise existential purposes and priorities. The multivariate models indicate that the stronger a person's self-efficacy and an internal attribution style, the more intense the readiness to confront with death and to examine own life attitudes; these effects are independent of personality traits.

In the next step, we focused on the influence of lockdown regarding the value-based responses for the second subsample ( $n=160$, during the COVID-19 lockdown). In the multivariate analyses there were few associations: the higher the reported psychological influence of lockdown, the stronger the association with the dimension "reconciliation with one's existence" of the AFEQT and "goal seeking" of the LAP-R, whereby age and self-confidence displayed independent positive associations with the assessed dimensions. When changing the perspective by means of multinomial regression models, the likelihood to report no influence from the lockdown on responses compared with a low or high influence is higher for "self-efficacy" "charity" "fulfillment of existence" and "death acceptance". We interpret these results as people who report no influence from the lockdown on value-based appraisals are more self-confident, are more able to focus on others than their own concerns, are more satisfied with their existence, and accept death as a part of life more naturally. However, we must consider that the lockdown restrictions in Germany were less restrictive than in Northern Italy, Spain, or New York.

The literature about relationships between the COVID-19 pandemic as a real threat for human lives and possible changes in life attitudes is scarce: it is mainly cross-sectional and based on the Meaning in Life (MiL) Questionnaire. In a Polish survey ( $N=317$, general population via open access forums on the Internet), mediation analyses suggested that "basic hope supports meaning in life and life satisfaction and the increase in the latter two factors results in lower anxiety and COVID-19 stress" (Trzebiński et al., 2020). There was also a protective effect of higher scores in meaning for nurses during the period of severe psychological pressure due to COVID-19; the current sense of meaning was higher than the search for meaning, based on support from significant others and by adaptation, meaning post-traumatic growth (Nowicki et al., 2020). In general, less social support and loneliness are associated with higher levels of distress, depression, and anxiety (Palgi et al., 2020). The general belief in a just world as the conviction that the world is fair to other people seems to reduce negative emotions and to increase positive emotions as a protective attitude during the COVID-19 pande- 
mic (Wang et al., 2020; Yu et al., 2020). A survey among Chinese students ( $N=$ 425 ) at two time points (4 months apart) during the COVID-19 pandemic using structural equation modelling showed that meaning in life was significantly related to positive mental health across time (Yu et al., 2020). Higher scores of meaning in life seem to deploy a protective effect against the negative psychological effects of a pandemic. The question that arises is whether a pandemic could trigger a more intensive reflection or confrontation with existential issues, especially confrontation with death (Valdés-Stauber, 2022), as a value of itself that could be of a personal relevance and provide a "deeper immunity" (Roman et al., 2020), independently of psychological implications. An Italian narrative inquiry $(N=$ 1393) based on the Semiotic Cultural Psychosocial Theory explored the meanings of people during lockdown and found four so-called "symbolic universes" labeled "reconsider social priorities" "reconsider personal priorities" "live with emergency" and "surviving a war" characterized by the pertinentization of two extremely basic issues: what the pandemic consists of (health emergency versus turning point) and its extent and impact (daily life vs. world scenario)" (Venuleo et al., 2020). These results are in line with the findings of present investigation as both of them highlight the reflexion about personal and interpersonal meanings during lockdown as liminal situation.

The main limitations of the study are: whether the selection of a lockdown could be considered as the right time point to explore personal changes during a pandemic under restrictive mobility conditions; the lack of follow up of the first sample $\left(t_{1}\right)$ until an adequate measurement point $\left(t_{2}\right)$ to assess possible statistically differences in value-based attitudes at the individual level; and the lack of structural equation modelling to take into account multiple influences at the same time and to consider autoregressive vectors controlled by variables to permit suggesting causal relationships depending on the direction of associations in the time series.

\section{Conclusion}

The strict lockdown that was imposed in many countries at the beginning of the COVID-19 pandemic, when vaccinations and drug treatments were not yet available, meant that millions of people suffered personal and social losses that could not otherwise be balanced. Research shows that psychosocial factors, age, personality and transdiagnostic factors such as self-efficacy or attribution styles are protective or stressful factors with regard to depression, anxiety or suicide risk. However, there is also growing literature that addresses the question of whether meanings, beliefs, values and significances might change in the face of the threat of the pandemic and severe lockdown measures. There is clear evidence that both robust personal attitudes and values have a protective effect on depression, anxiety and suicide risk. The present study compares attitudes towards death and life in the period before and during the lockdown. As the research design could not be planned prospectively due to the surprising pandemic development, it has some 
methodological limitations; nevertheless, the reanalysis of data under statistical control (as it concerned two different groups of people) shows that the pandemic in connection with the lockdown triggers a personal reflection on existential issues, especially on the meaning of death, on one's own goals in life, on self-transcendence and on concerns for loved ones. On the other hand, the study shows that the stronger some transdiagnostic characteristics such as self-efficacy or life satisfaction are, the lower the negative influence of the lockdown and pandemic, which could be the protection against the lost of mental balance, as other studies confirmed.

To conclude this paper, the authors would like to quote the renowned New York psycho-oncologist William Breitbart during the severe pandemic situation in his hometown:

Now a year later, we are painfully learning, on a global scale, that human life, our own lives, now, are vulnerable and at risk of ending at any moment. We cannot avoid what has always been the truth of our existence of our lives. We can no longer easily avoid the imperative that in living and creating our lives, we must do so in the context that death is a part of life. We must develop our attitude towards both living and dying throughout our lives. We must strive to find meaning both in our lives and in our deaths. Death makes life and living more precious and urgent. Death helps teach us what is truly important in life and who we are as human beings. This COVID-19 pandemic has taught us that nothing is more important than love, family, community, and communication [...] finally, the issue of accepting mortality. During this pandemic, I have been thinking a lot of my late parents. They've come to mind for several reasons. Initially, I tried to put this unprecedented pandemic into some relatable historical context. I began to think of my experience, our experience, with this life changing, life threatening pandemic, as being somewhat analogous to the experience of my parents during the Holocaust [...] everything is impermanent; and that includes pandemics and wars as well as well-performing economies and life itself. And so, this COVID-19 pandemic will also one day be over, and we will return to a perhaps new normal life that resembles our pre-COVID-19 lives. Hopefully, it will be to lives that have been not merely traumatized but also somewhat transformed for the better. A "Change is Gonna Come" and hopefully, it will be with a renewed sense of love, compassion, gratitude, kindness, and care for each other and our planet.

(William Breitbart: Life and Death in the Age of COVID-19 (Breitbart, 2020)).

\section{Declarations}

- This investigation was approved by the Ethics Committee of the University of Ulm (registration number 02/19);

- All authors consent for publication;

- No competing interests;

- No funding for this study;

- Author's contributions: Juan Valdés-Stauber: conceptualisation, methodology, formal analysis (statistics), original draft, review and editing; Jakob Böttinger: 
training in methodology, data collection in middle aged adults; Sarah Kramer: training in methodology, data collection in young adults.

\section{Conflicts of Interest}

The authors declare no conflicts of interest regarding the publication of this paper.

\section{References}

Breitbart, W. (2020). Life and Death in the Age of COVID-19. Palliative \& Supportive Care, 18, 252-253. https://doi.org/10.1017/S1478951520000334

Brooks, S., Webster, R. K., Smith, L. E., Woodland, L., Wessely, S., Greenberg, N. et al. (2020). The Psychological Impact of Quarantine and How to Reduce It: Rapid Review of the Evidence. The Lancet, 395, 912-920. https://doi.org/10.1016/S0140-6736(20)30460-8

Chew, Q. H., Wei, K. C. C., Vasoo, S., Chua, H. C., \& Sim, K. (2020). Narrative Synthesis of Psychological and Coping Responses towards Emerging Infectious Disease Outbreaks in the General Population: Practical Considerations for the COVID-19 Pandemic. Sin gapore Medical Journal, 61, 350-356. https://doi.org/10.11622/smedj.2020046

Coutard, B., Valle, C., de Lamballerie, X., Canard, B., Seidah, N. G., \& Decroly, E. (2020). The Spike Glycoprotein of the New Coronavirus 2019-nCoV Contains a Furin-Like Cleavage Site Absent in CoV of the Same Clade. Antiviral Research, 176, Article ID: 104742. https://doi.org/10.1016/j.antiviral.2020.104742

Czeisler, M. E., Lane, R. I., Petrosky, E., Wiley, J. F., Christensen, A., Njai, R. et al. (2020). Mental Health, Substance Use, and Suicidal Ideation during the COVID-19 Pandemic United States. MMWR, 69, 1049-1057. https://doi.org/10.15585/mmwr.mm6932al

Gudbjartsson, D. F., Norddahl, G. L., Melsted, P., Gunnarsdottir, K., Holm, H., Eythorsson, E. et al. (2020). Humoral Immune Response to SARS-CoV-2 in Iceland. The New England Journal of Medicine, 383, 1724-1734. https://doi.org/10.1056/NEJMoa2026116

Hauser, A., Counotte, M. J., Margossian, C. C., Konstantinoudis, G., Low, N., Althaus, C. L. et al. (2020). Estimation of SARS-CoV-2 Mortality during the Early Stages of an Epidemic: A Modeling Study in Hubei, China, and Six Regions in Europe. PLOS Medicine, 17, e1003189. https://doi.org/10.1371/journal.pmed.1003189

Helms, J., Tacquard, C., Severac, F., Leonard-Lorant, I., Ohana, M., Delabranche, X. et al. (2020). High Risk of Thrombosis in Patients with Severe SARS-CoV-2 Infection. Intensive Care Medicine, 46, 1089-1098. https://doi.org/10.1007/s00134-020-06062-x

Humphrey, A., \& Vari, O. (2021). Meaning Matters: Self-Perceived Meaning in Life, Its Predictors and Psychological Stressors Associated with the COVID-19 Pandemic. Behavioral Sciences (Basel), 11, 50. https://doi.org/10.3390/bs11040050

Huremović, D. (2019). Psychiatry of Pandemics: A Mental Health Response to Infection Outbreak. Springer Nature Switzerland. https://doi.org/10.1007/978-3-030-15346-5

Imber-Black, E. (2020). Rituals in the Time of COVID-19: Imagination, Responsiveness, and the Human Spirit. Family Process, 59, 912-921.

https://doi.org/10.1111/famp.12581

Klok, F. A., Kruip, M., van der Meer, N. J. M., Arbous, M. S., Gommers, D., Kant, K. M. et al. (2020). Incidence of Thrombotic Complications in Critically Ill ICU Patients with COVID-19. Thrombosis Research, 191, 145-147. https://doi.org/10.1016/j.thromres.2020.04.013 
Kovaleva, A., Beierlein, C., Kemper, C. J., \& Rammstedt, B. (2012). A Brief Scale to Assess Locus of Control. The Internal-External-Locus of Control-Scale. GESIS Working Papers. https://www.ssoar.info/ssoar/handle/document/31209

Krampe, H., Danbolt, L. J., Haver, A., Stålsett, G., \& Schnell, T. (2021). Locus of Control Moderates the Association of COVID-19 Stress and General Mental Distress: Results of a Norwegian and a German-Speaking Cross-Sectional Survey. BMC Psychiatry, 21, 437. https://doi.org/10.1186/s12888-021-03418-5

Lai, J., Ma, S., Wang, Y., Cai, Z., Hu, J., Wei, N. et al. (2020). Factors Associated with Mental Health Outcomes among Health Care Workers Exposed to Coronavirus Disease 2019. JAMA Network Open, 3, e20397. https://doi.org/10.1001/jamanetworkopen.2020.3976

Lee, A. M., Wong, J., McAlonan, G. M., Cheung, V., Cheung, C., Sham, P. C. et al. (2007). Stress and Psychological Distress among SARS Survivors 1 Year after the Outbreak. The Canadian Journal of Psychiatry, 52, 233-240. https://doi.org/10.1177/070674370705200405

Man, M. A., Toma, C., Motoc, N. S., Necrelescu, O. L., Bondor, C. I., Chis, A. F. et al. (2020). Disease Perception and Coping with Emotional Distress during COVID-19 Pandemic: A Survey among Medical Staff. International Journal of Environmental Research and Public Health, 17, 4899. https://doi.org/10.3390/ijerph17134899

Mehnert, A., Müller, D., \& Koch, U. (2007). Measuring Meaning-Based Coping and Life Attitudes. Psychometric Evaluation of the German Version of the Life Attitude Profile-Revised (LAP-R) in a Representative Sample of Breast Cancer Patients. Zeitschrift für klinische Psychologie, Psychiatrie und Psychotherapie, 36, 176-188.

https://doi.org/10.1026/1616-3443.36.3.176

Nowicki, J., Slusarska, B., Tucholska, K., Naylor, K., Chrzan-Rodak, A., \& Niedorys, B. (2020). The Severity of Traumatic Stress Associated with COVID-19 Pandemic, Perception of Support, Sense of Security, and Sense of Meaning in Life among Nurses: Research Protocol and Preliminary Results from Poland. International Journal of Environmental Research, 17, 6491. https://doi.org/10.3390/ijerph17186491

Palgi, Y., Shrira, A., Ring, L., Bodner, E., Avidor, S., Bergman et al. (2020). The Loneliness Pandemic: Loneliness and Other Concomitants of Depression, Anxiety and Their Comorbidity during the COVID-19 Outbreak. Journal of Affective Disorders, 275, 109-111. https://doi.org/10.1016/j.jad.2020.06.036

Prati, G., \& Mancini, A. D. (2021). The Psychological Impact of COVID-19 Pandemic Lockdowns: A Review and Meta-Analysis of Longitudinal Studies and Natural Experiments. Psychological Medicine, 51, 201-211. https://doi.org/10.1017/S0033291721000015

Rammstedt, B. (2007). The 10-Item Big Five Inventory (BFI-10): Norm Values and Investigation of Sociodemographic Effects Based on a German Population Representative Sample. European Journal of Psychological Assessment, 23, 193-201.

https://doi.org/10.1027/1015-5759.23.3.193

Roman, N. V., Mthembu, T. G., \& Hoosen, M. (2020). Spiritual Care-“A Deeper Immunity"-A Response to Covid-19 Pandemic. African Journal of Primary Health Care \& Family Medicine, 12, a2456. https://doi.org/10.4102/phcfm.v12i1.2456

Romppel, M., Herrmann-Lingen, C., Wachter, R., Edelmann, F., Dungen, H. D., Pieske, B. et al. (2013). A Short form of the General Self-Efficacy Scale (GSW-6): Development, Psychometric Properties and Validity in an Intercultural Non-Clinical Sample and a Sample Of patients at Risk for Heart Failure. Psycho-Social-Medicine, 10, Doc01. https://doi.org/10.1037/t69316-000

Rossi, R., Jannini, T. B., Socci, V., Pacitti, F., \& Lorenzo, G. D. (2021). Stressful Life Events and Resilience during the COVID-19 Lockdown Measures in Italy: Association with 
Mental Health Outcomes and Age. Front Psychiatry, 12, Article ID: 635832. https://doi.org/10.3389/fpsyt.2021.635832

Schnell, T., \& Krampe, H. (2020). Meaning in Life and Self-Control Buffer Stress in Times of COVID-19: Moderating and Mediating Effects with Regard to Mental Distress. Front Psychiatry, 11, Article ID: 582352. https://doi.org/10.3389/fpsyt.2020.582352

Schulte-Schrepping, J., Reusch, N., Paclik, D., Baßler, K., Schlickeiser, S., Zhang, B. et al. (2020). Severe COVID-19 Is Marked by a Dysregulated Myeloid Cell Compartment. Cell, 182, 1419-1440. https://doi.org/10.1016/j.cell.2020.08.001

Shang, J., Wan, Y., Luo, C., Ye, G., Geng, Q., Auerbach, A., Li, F. et al. (2020). Cell Entry Mechanisms of SARS-CoV-2. PNAS USA, 117, 11727-11734. https://doi.org/10.1073/pnas.2003138117

Shi, L., Lu, Z. A., Que, J. Y., Huang, X. L., Liu, L., Ran, M. S. et al. (2020). Prevalence of and Risk Factors Associated with Mental Health Symptoms among the General Population in China during the Coronavirus Disease 2019 Pandemic. JAMA Network Open, 3, e2014053. https://doi.org/10.1001/jamanetworkopen.2020.14053

Solomou, I., \& Constantinidou, F. (2020). Prevalence and Predictors of Anxiety and Depression Symptoms during the COVID-19. International Journal of Environmental Research and Public Health, 17, 4924. https://doi.org/10.3390/ijerph17144924

Stabenow, U. (2021). The Confrontation with Personal End of Life in Dying People-Comparison between Individuals in Palliative Care and Nursing Home Residents by Means of the "Anticipatory Farewell to Existence Questionnaire". Accomplished Doctoral Dissertation, University of Ulm.

Tang, N., Li, D., Wang, X., \& Sun, Z. (2020). Abnormal Coagulation Parameters Are Associated with Poor Prognosis in Patients with Novel Coronavirus Pneumonia. Journal of Thrombosis and Haemostasis, 18, 844-847. https://doi.org/10.1111/jth.14768

Tay, M. Z., Poh, C. M., Rénia, L., MacAry, P. A., \& Ng, L. F. P. (2020). The Trinity of COVID-19: Immunity, Inflammation and Intervention. Nature Reviews Immunology, 20, 363-374. https://doi.org/10.1038/s41577-020-0311-8

Trzebiński, J., Cabański, M., \& Czarnecka, J. (2020). Reaction to the COVID-19 Pandemic: The Influence of Meaning in Life, Life Satisfaction, and Assumptions on World Orderliness and Positivity. Journal of Loss and Trauma, 25, 544-557. https://doi.org/10.1080/15325024.2020.1765098

Valdés-Stauber, J. (2022). Thanatological Definitions as a Contribution to a Humanisation of Medicine at the End of Life. Spiritual Care, 11, 46-57.

Valdés-Stauber, J., Stabenow, U., Kramer, S., Böttinger, J., \& Kilian, R. (2021). Divergent Patterns of Confrontation with Death Using the Anticipated Farewell to Existence Questionnaire (AFEQT): A Cross-Sectional Comparative Study of Four Samples with Increasing Proximity to Death. BMC Palliative Care, 20, Article No. 125. https://doi.org/10.1186/s12904-021-00818-y

Vardhana, S., \& Wolchok, J. D. (2020). The Many Faces of the Anti-COVID Immune Response. Journal of Experimental Medicine, 217, e20200678. https://doi.org/10.1084/jem.20200678

Venuleo, C., Marinaci, T., Gennaro, A., \& Palmieri, A. (2020). The Meaning of Living in the Time of COVID-19. A Large Sample Narrative Inquiry. Frontiers in Psychology, 11, Article ID: 577077. https://doi.org/10.3389/fpsyg.2020.577077

Verity, R., Okell, L. C., Dorigatti, D., Winskill, P., Whittaker, C., Imai, N. et al. (2020). Estimates of the Severity of Coronavirus Disease 2019: A Model Based Analysis. The Lancet Infectious Diseases, 20, 669-677. https://doi.org/10.1016/S1473-3099(20)30243-7

Vetter, P., Vu, D. L., L'Huillier, A. G., Schibler, M., Kaiser, L., \& Jacquerioz, F. (2020). 
Clinical Features of COVID-19. The Wide Array of Symptoms Has Implications for the Testing Strategy. British Medical Journal, 369, m1470.

https://doi.org/10.1136/bmj.m1470

Wang, J., Wang, Z., Liu, X., Yang, X., Zheng, M., \& Bai, X. (2020). The Impacts of a COVID-19 Epidemic Focus and General Belief in a Just World on Individual Emotions. Personality and Individual Differences, 168, Article ID: 110349. https://doi.org/10.1016/j.paid.2020.110349

Xiong, J., Lipsitz, O., Nasri, F., Lui, L. M. W., Gill, H., Phan, L. et al. (2020). Impact of COVID-19 Pandemic on Mental Health in the General Population: A Systematic Review. Journal of Affective Disorders, 277, 55-64.

https://doi.org/10.1016/j.jad.2020.08.001

Yu, Y. J., Yu, Y. J., \& Lin, B. (2020). Cross-Lagged Analysis of the Interplay between Meaning in Life and Positive Mental Health during the COVID-19 Epidemic. Asian Journal of Psychiatry, 54, Article ID: 102278. https://doi.org/10.1016/j.ajp.2020.102278 